\title{
A Good Practice Project Related To Sustainable Solutions to Address the Global Pandemic and Achieve Agenda 2030
}

\author{
Elena Sturchio ${ }^{1}$, Miriam Zanellato ${ }^{1}$, Priscilla Boccia ${ }^{1}$ \\ ${ }^{1}$ Department of Technological Innovation and Safety of Plants, Product and Anthropic Settlements (DIT), Italian Workers' \\ Compensation Authority (INAIL), Rome, Italy \\ e.sturchio@inail.it; m.zanellato@inail.it \\ p.boccia@inail.it
}

\begin{abstract}
The COVID-19 pandemic has stressed the relevance of performing a deep review regarding the robustness of current food production and consumption systems. The health crisis derived from the outbreak has directly influenced lifestyle habits throughout the planet, including food consumption and its related food loss and waste (FLW) generation, mainly by the compulsory "staying home". The reduction of FLW is a key to achieving sustainability, and more recently a main objective of the EU Farm to Fork (F2F) strategy for sustainable food, which aims at making food systems fair, healthy and environmentally-friendly. In this context, EC will strengthen educational messages on the importance of reducing food waste within school.

Italian Project: "Food waste, consumer attitudes and behaviour: a project exploring the reasons linked to consumer-related food waste, involving Italian schools" (named SPAIC), was carried out by Ministry of Health, INAIL and three Italian high schools (from 2016 to 2020). SPAIC project was chosen by Food and Agriculture Organization of the United Nations (FAO) as good practice and lesson on food security and nutrition policy implementation in Europe and Central Asia region. Reducing the amount of wasted food is a key element in developing programs of global environmental, ethical and sustainable food system production. Food waste occurs at all stages of the food production, starting from harvesting, through manufacturing and distributing and finally consumption, but the largest contribution to food waste occurs surprisingly at home in the developed countries. To reduce consumer-related food waste, it is necessary to have a clear understanding of the factors influencing food waste-related consumer perceptions and behaviours. The Project focused on the food consumption to explore the reasons of food waste production at family level in order to overcome food-wasting behaviour. Then, the aim was to point out options to design prevention measures by the responsible involvement of the students.
\end{abstract}

Keywords: food waste, high schools, emotional based nudge, consumers' behaviour, household, COVID-19 pandemic, sustainability.

\section{Introduction}

Food waste has received increasing attention over the past few years involving stakeholders like scientists, researchers, consumers, organizations and finally the governments that have only recently designed specific laws. In Italy, the law $\mathrm{n}^{\circ} 166$ of August 19, 2016 (entered into force on September 14, 2016) focuses the target to reduce waste during production, processing, distribution and administration of food and pharmaceutical products. Then, reducing the amount of wasted food is a key element in developing programs of global environmental, ethical and sustainable food system production. Food waste occurs at all stages of the food production, starting from harvesting, through manufacturing and distributing and finally consumption, but the largest contribution to food waste in the developed countries occurs surprisingly at home. Food waste generation that occurs in large-scale retail distribution and at home is mostly avoidable because large quantities of produced food are discarded when it is still edible. Waste reduction at the level of household consumption is critical because the environmental impact accumulates throughout each of the following stages of the food life cycle [1]. Given the magnitude of waste, any reductions in food and drink waste at a household level may have a substantial positive environmental effect.

As a cause of negative economic, environmental, and social effects, food waste is considered one of the priority sustainability issues that needs to be addressed. Analysis of data from across Europe generated an estimate of food waste in the EU of 88 million tonnes, annually. The sector contributing the most to yearly food waste is households (47 million tonnes \pm 4 million tonnes) [2]. 
In developed countries, consumers are one of the biggest sources and they are directly/indirectly responsible of food waste. To reduce consumer-related food waste, it is necessary to have a clear understanding of the factors influencing food waste-related consumer perceptions and behaviours.

The COVID-19 pandemic has stressed the relevance of performing a deep review regarding the robustness of current food production and consumption systems. In fact, the health crisis derived from the outbreak has directly influenced lifestyle habits throughout the planet, including food consumption and its related food loss and waste (FLW) generation, mainly by the compulsory "staying home".

Recent studies revealed that food consumption and food waste behaviours, in some cases, have been more virtuous, showing that the Covid-19 pandemic has enhanced people's attitude toward food waste reduction and more sustainable consumption models. During the Covid-19 lockdown, people had adequate time to improve food planning and storage operations, select food programs, etc.. By taking advantage of such a disaster, awareness on previous unsustainable behaviour could increase, thus enhancing awareness about the food waste issue, both at the industrial and household levels $[3,4,5,6]$. Furthermore, the COVID-19 crisis has revealed an unprecedented flow of solidarity. Considering that the number of vulnerable social groups and families has rocketed in the matter of weeks, it is imperative to apply the FLW management hierarchy throughout food supply chains, favouring secondary feeding strategies by means of effective donations and, fostering, therefore, the circularity of the agri-food sector.

According to the United Nations' Sustainable Development Goal (SDG) 12.3 [7], regarding halving per capita global food waste at the retail and consumer levels by 2030 [8], the Italian Project "Food waste, consumer attitudes and behaviour: a project exploring the reasons linked to consumer-related food waste, involving Italian schools" (named SPAIC) was carried out, in partnership with government (Ministry of Education and Ministry of Health) for the empowerment of young people and their education. The SPAIC Project supported the idea that the sustainability starts with the individuals, not only at the farm or processing levels but also at the domestic consumption stage.

The aim was to involve high school students in order to raise their awareness of the multiple aspects of the food waste problem and encourage them to enhance their creativity to promote positive changes and good practices for a better distribution of the resources of our planet. Finally, the Project wanted to raise awareness of the nutritional aspects of food.

In the Project, different schools were chosen to study whether the difference in socioeconomic status has a reflection on habits about food waste (shopping, leftovers, food preservation, donation) as well as on perception of individual responsibility towards food waste.

Students were encouraged to have familiarity with the fragility of their territory in order to study innovative solutions first of all for disadvantaged people. Starting from the evidence that the attitudes and behaviour can significantly affect the amount of food directly and indirectly wasted, the students were stimulated to become messengers of good behavioural practices, for the protection of their health and the family and the territory around them, with attention to the protection of fragile categories.

The project was planned according to the interests, perceptions and curiosity of the students, focusing on their insights to design useful "products", which would transform the idea into concrete social utility tools, according to the European conception of Science useful to the progress and growth.

Thanks to the successful results achieved and its high educational value, SPAIC project was chosen by Food and Agriculture Organization of the United Nations (FAO) as good practice and lesson on food security and nutrition policy implementation in Europe and Central Asia region [9].

\section{Objectives}

The SPAIC project was carried out by INAIL/DIT, Ministry of Health and three Italian Schools. The project started on 12 October 2016, ended in 2020, and aligns itself with the overall objectives of the Italian specific law.

The overall Project aim was to focus on food waste in the consumption stage, to explore the reasons of food waste at the level of household consumption level. Possible solutions for corrective intervention of family behaviour through responsible involvement in the analysis and possible solutions of students at the "pre-university" level, were induced. 
Prevention measures were designed and at the same time emphasized the need to respect nutritional rules in order not to "waste one's health".

The students were encouraged to have critical and responsible attitudes and to be aware of their choices, which must always be guided by correct documentation.

The Project consisted of two specific objectives:

1) information/knowledge transfer: provide scientific information on "Food waste" that occurs at all stages of the food life cycle, starting from harvesting, through manufacturing and distributing and finally consumption.

2) dissemination/education: disseminate a good behaviour model, in efficient and effective way, regarding the issue of food waste and compliance with related nutrition rules, among classmates, youngsters and families, in a prevention perspective of the contribution to food waste at households and at the same time forming a specific awareness of the important correcting role that new generations "have to" play in this field (Fig. 1).

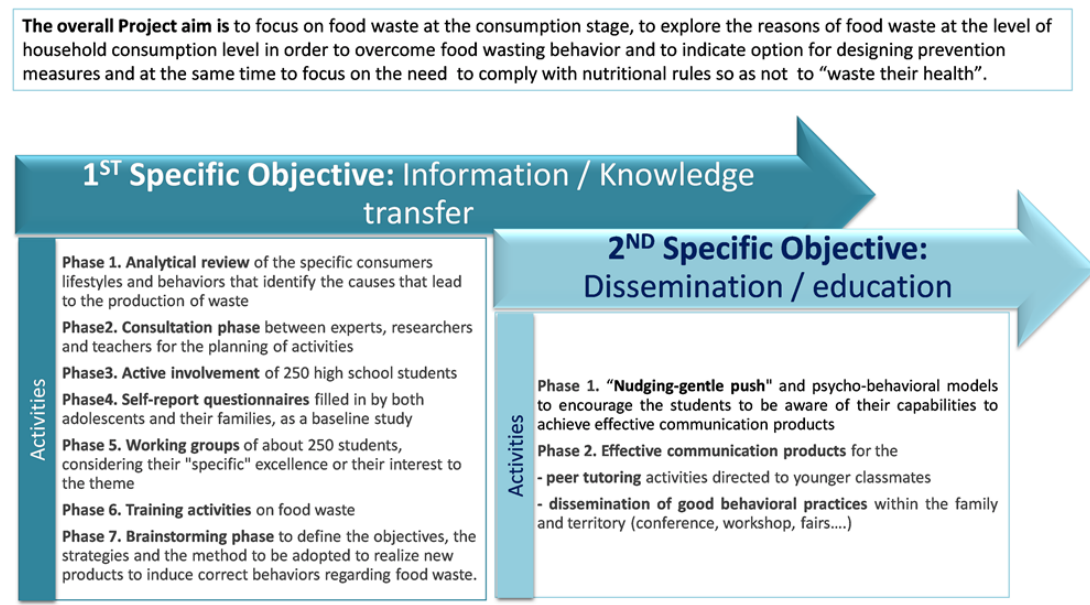

Fig. 1: A schematic representation of overall and specific objectives of the SPAIC Project.

The learning methodology consists in non-formal and informal education that offers an experiential learning, which aims to achieve knowledge by "experimenting." The knowledge is shared in a "horizontal" and "multidirectional" relationship among teachers, educators, experts and firstly students, that develop critical attitude of thought and an active participation (Fig. 2).

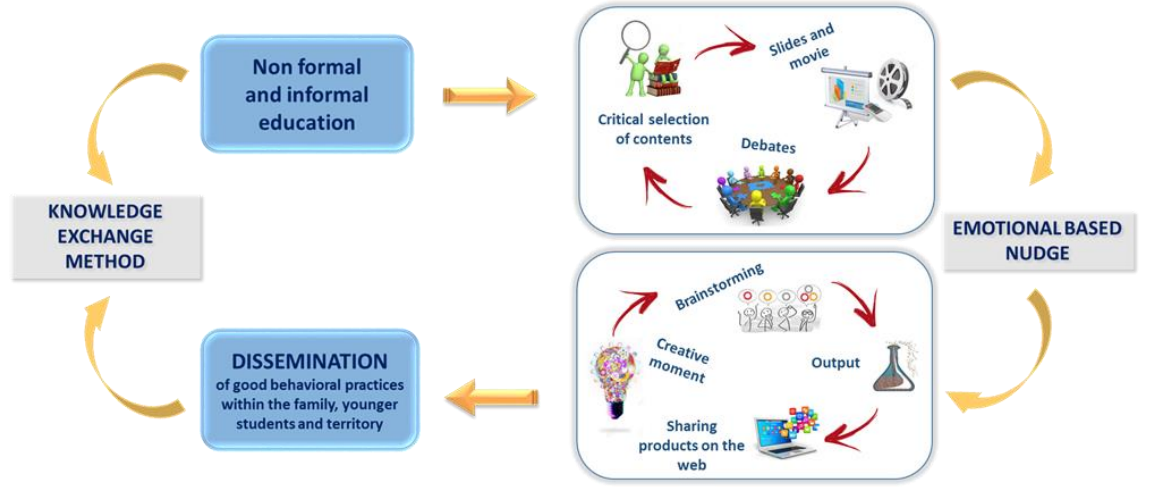

Fig. 2: A lifelong learning methodology. Students, teachers and experts, defined the strategies and the method to be adopted to realize new products to induce correct behaviours regarding food waste. 
Furthermore, the SPAIC project adopts the "nudging" methodology, also called "gentle push" that can offer a way behave properly (a kindly suggested model that is not refused a priori as taxation authority), and therefore is effective culturally acquirable. In fact, behavioural economist Richard Thaler and legal scholar Cass R. Sunstein outlined the for more innovative and less coercive government interventions to shape people's behaviour.

A central premise behind nudge theory is that people frequently behave in an unpredictable way and not always in their own best interest. Employing behavioural insight as indicator of human behavioural response makes it possible to shape behaviours, by changing the "choice architecture" of those people. These changes may prompt people to make better decisions about health, wealth and happiness, in their own declared interest [10].

Thaler and Sunstein provide a flexible definition of what a nudge is: "A nudge, as we will use the term, is an aspect of the choice architecture that alters people's behaviour in a predictable way without forbidding any options or significantly changing their economic incentives. To count as a mere nudge, the intervention must be cheap and easy to avoid. Nudges are not mandates. Nudges can be implemented by a wide range of actors, come in a wide range of forms and seek to achieve a wide range of outcomes" [11].

The choice architects are therefore supposed to rearrange the physical and social environment in order to make people change behaviour, a kind of soft paternalism that does not include coercion, a benignly intentioned manipulation meant to improve the direction of peoples' choices while maintaining freedom of choice [12]. Nudge previously has been examined in individual studies for its capacities to positively influence behaviours including decreasing tobaccouse, increasing physical activity and encouraging financial planning, instead in SPAIC project this model was used in a" wellness based" study on the food waste [13].

\section{Material and Methods}

Three high schools from Italian Latium region were selected, characterized by different socioeconomic status and fields of education: a private school of Art situated in the Rome centre (IIS Sant'Orsola), a Cinematographic high school in a suburb location (IIS Cine-Tv Rossellini) and a Biotechnology school in Rome province (IIS Largo Brodolini, Pomezia). The students involved were encouraged to study whether the difference in localization and socioeconomic status has a reflection on habits about food waste (shopping, leftovers, food preservation) as well as on perception of individual responsibility towards food waste. In each school, project activities consisted of two specific objectives (Fig. 1).

The first specific objective provided "information/knowledge transfer".

Phase 1. An analytical review of the specific consumer's lifestyles and behaviours that identify the causes that lead to the production of food waste, was performed. This material was elaborated to be transferred to a selected group of students. In particular, starting from the evidence that the attitudes and behaviours can significantly affect the amount of food directly and indirectly wasted, scientific literature was reviewed to extrapolate the guidelines for achieving the chosen goals, including specific surveys on social media and on the corrective actions already adopted in other case studies.

Phase 2-3. After a consultation phase between experts, researchers and teachers for the planning of activities, followed the active involvement of 250 high school students of $3 \mathrm{rd}$ and $4^{\text {th }}$ classes followed.

Phase 4. Data about food waste habits and the perception of one's responsibility about it were collected with selfreport questionnaires, filled in by both adolescents and their families, as a baseline study. Taking in account the questionnaire, realized in collaboration with a pool of biologists, nutritionists and behavioural economists of the Ispra Joint Research Center and with diet technologists of the Karlsruhe Institut für Technologie [14,15,16], modified and integrated into some questions, two closed questionnaires were prepared to describe the overall sample at the beginning of the intervention (baseline collection):

- a questionnaire of 30 items to investigate habits, attitudes, perceptions and potential for action around the topic of food waste administered to teenagers aged 16-18 (student questionnaire); 
- a questionnaire of 35 items investigating the same issues and collecting some socio-economic data, filled by the students' parents (family questionnaire) to represent the specific habits in a roman area.

The questionnaires describe four different areas of interest: Food habits and attitudes and spending, Food waste, Perception of responsibility, Prevention of food waste.

Phase 5. Then, lessons regarding food waste impacts on the environment, on loss of resources and on its causes were were given to a selected group of students, in order to raise their awareness on food waste problem. After the presentation of the SPAIC Project objectives, working groups were formed involving students chosen among about 250 of them, considering their "specific" excellence (according to their teachers) and their interest to the theme.

Phase 6. Teachers and researchers proceeded then to organize training activities on food waste, correlating it to the concept of sustainability and underlining its negative economic, environmental and social impacts. The learning methodology consisted of both non-formal and informal education that offered an experiential learning, which aimed to achieve knowledge by "experimenting". The supplied knowledge was shared in a "horizontal" and "multidirectional" relationship, among teachers, educators, experts and firstly students (Fig. 2), developing critical attitude of thought and an active participation, through this lifelong learning methodology.

Phase 7. During brainstorming phase, students, teachers and experts defined the objectives, the strategies and the method to be adopted to realize new products to induce correct behaviours regarding food waste. It's of great interest for educators that this experiential method obliges students to use formal education, necessary for the realization of their creative products.

The second specific objective "dissemination/education".

Phase1. During project activities, was investigated the need to be supported by expert researchers in the field, both by "nudging -gentle push" and by psycho-behavioural models to encourage the students to be aware of their capabilities to achieve effective communication products. Students showed an interest in the food waste theme and in the realization of our project but lacked in motivation and awareness in their own capabilities to become active participants of the project.

Two different kind of nudges were proposed to promote the active participation of the students: a nudge that involved physical/environmental factors and a nudge based on motivational/emotional factors. The suggested environmental nudge consisted in the creation of a space inside the school where students may consume meals prepared at home (the lack of a such dedicated space could encourage the students to buy food at the school bar or from a vending machine placed inside the school that offers foods that are mostly unhealthy and not environmental friendly).

The motivational/emotional based nudge consisted of meetings with a motivator, a person who works with the students at an emotional and creative level to inspire them about their own potential to be active participants in choices that are relevant for them and for the whole environment. These meetings were designed to make students thrust in their capabilities to make important changes in their lives. The two nudges are further described and compared below.

Phase 2. Creation of effective communication products for the dissemination of good behavioural practices within the family and territory, enhanced by peer tutoring activities directed to younger classmates for food waste reduction and environmental and health risk prevention. These products were designed to be later widespread through the media channels, supported by researchers' websites (http://innsite.it).The WEB was also used as a tool for promotion of strategies and initiatives conducted by these pilot schools (inside their living environment), in order to realize a model of education replicable by other schools.

\section{Results and Discussion}

At the beginning of the present study, habits and knowledge about food waste were assessed through self-report questionnaires, filled out both by the students and their families. From a preliminary qualitative assessment of our 30 items questionnaire (filled by 212 students of the three schools at the beginning of the project), the students seem to have a low sense of responsibility for the food waste they produce. On a 1 to 5 scale, (level1=not responsible at all; level5=completely responsible) 41,51\% assessed on level 2 and 32,55\% on level 3. However most of the students $(58,96 \%)$ showed a clear willingness to be informed about environmental negative impacts of food waste [17]. It is interesting to underline that the results of the family questionnaire achieved at local level (filled by 114 families) are almost comparable to the data reported 
by Waste Watcher 2016 at national level, some of the questionnaire results about food habits and waste at family level are shown in the figure 3.

Main causes of household food waste
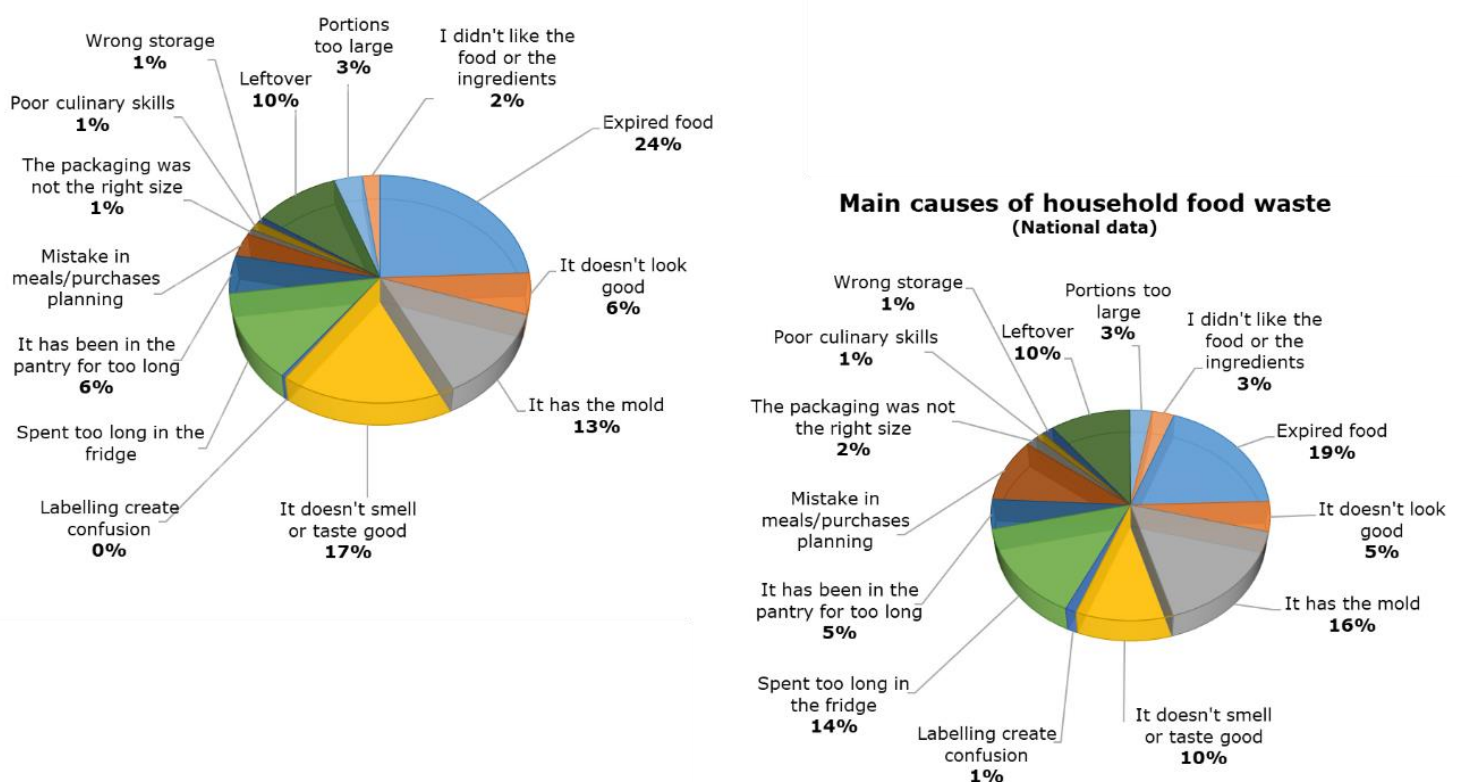

Fig. 3. Percentages of main causes of household food waste at local and National level, obtained by family questionnaires.

Every Project action required the synergistic involvement of the main "actors" (students, teachers, experts and families) called to dialogue and to contribute to common goals. As positive training result correlating to the issue of food waste sustainability and its negative economic, environmental and social impacts, students produced social network interactive products or videos, addressed to their classmates and generally to youngsters. Some of the outputs of the Project include leftover food recipes, amusing street interviews, a photo exhibition, a game on food waste for younger generation, the creation of a learning unit on food waste, five short films and two rap songs. These products were presented directly by the students in conferences, meetings involving other schools, national workshop and exhibitions in order to observe its efficacy on food waste related behaviours inside the community.

A "nudge" approach was applied for enabling and encouraging students, families and people to be involved in promoting attitudes and behaviours that prevent food waste. We observed that the Nudge based on the manipulation of the environment was less powerful than the one based on emotional and motivational factors. After a first interest in the creation of a dedicated space for the consumption of food brought from home, the project dropped. We hypothesize that the failure of this kind of Nudge was related not only to organizational matters but also mainly because the students did not feel excited and emotionally involved. On the contrary, the creation of informational and educational products in which the students used their expressive means and carried out their ideas about what was meaningful for them was welcomed with great enthusiasm. The produced material was of high quality and was characterized by great creativity and had a great emotional impact. The evaluation of the project's key performance indicators shows that the students of all the three schools involved have been adequately motivated by the INAIL experts and thanks to the fruitful collaboration of the teachers and school managers, who enthusiastically supported the project, they were planning creative, innovative ideas and were spreading them on their territory (Table 1). 
Table 1: Project's key performance indicators

\begin{tabular}{|l|}
\hline SPECIFIC OBJECTIVE 1 \\
\hline Motivational indicators (Phases 1-6) \\
\hline $\begin{array}{l}\text { Number of teachers involved (14)/Number of teachers contatcted (5); } \\
\text { Number of students applying for participation in the project (104) / Total number of students contacted (273) } \\
\text { Number of students selected for brainstorming (>104)/ Total number of students contacted (104); }\end{array}$ \\
\hline Educational indicators (Phase 7) \\
\hline Number of relevant proposals advanced in the brainstorming phase (12)/ Total number of proposals (12) \\
\hline SPECIFIC OBJECTIVE 2 \\
\hline Effective design development indicators (Phases 2) \\
\hline Number of developed products (>12)/ Number of proposals advanced in the brainstorming phase (12) \\
\hline Indicators of effectiveness of product communication (Phases 2) \\
\hline Participation in conferences (8) / Participation in scheduled conferences (2) \\
\hline
\end{tabular}

Pushing education and skills development of the young people in the age of becoming the next actors of the post Covid world is considered the main response key to the challenge they have to face. Education is mainly addressed to their conscience of being part of a community that need the skill, the competence and the generosity of everybody. SPAIC represents an innovative model tool to positively connect minds in a circular path.

The bullet points of SPAIC methodology are:1. Connecting Minds: The construction of a team of collaborators who work in synergy and harmony is considered one of the most important aspects for the success of an educational project. 2. Information/Knowledge transfer. The lifelong learning methodology 3. Inspire and Motivate: To encourage and inspire the students about their potential to be active participants in choices 4. Induce seemingly very small changes that can produce great effects. The methodology to make students able to thrust in their capabilities 5. Let Beauty flow. The need arose from the students was to put the theme of Beauty, Harmony, the Common Good before all the negative drifts that the theme of food waste can cause. 6. To Create a Sustainable future. Disseminate a good behaviour model, in efficient and effective way, regarding the issue about food waste.

\section{Conclusions}

Creativity, risk taking adaptability and innovation capacity, problem solving skills, skills related to effective teamwork and sharing information and knowledge, may all be key competitive advantages for the next generation people, starting from teenagers. To make the best of this potential, it is essential that schools and educational institutions, as well as non-formal way of learning, empower Europe's young innovators with the skills they need from early on in life. The challenge addressed by this Project is to improve learning and teaching in innovation-related skills for young boys and girls at the age of secondary education through the design and piloting of new innovative way of skills education, including technologies, process and relations.

SPAIC methodology was of great interest in this period of pandemic, as it is capable of inducing virtuous behaviour in young people, changing lifestyles, increasing the sense of responsibility, activating solidarity circuits.

SPAIC Project can be adopted and adapted in different context through specific Toolkit realized thanks to the creativity and sensitivity of the students.

The Toolkit includes a manual on the "SPAIC methodology" for schools wishing to replicate the Project and guidelines for teachers and tutors, in-depth material on nutrition and correct lifestyles, and a video tutorial to facilitate learning and understanding of the method and content treated. SPAIC toolkit could be downloaded by web site (www.insite.it) 
The SPAIC Project, that will be presented at Dubai EXPO 2021, has a beautiful previous success story. It could be an important stimulus to support the ideas the skills the creativity and the enthusiasm of young people pushing them to be protagonists of a sustainable development.

\section{References}

[1] H. Williams and F. Wikström, "Environmental impact of packaging and food losses in a life cycle perspective: a comparative analysis of five food items", J. Clean. Prod., vol. 1, n. 19, pp 43-48. 2011. http://dx.doi.org/10.1016/j.jclepro.2010.08.008.

[2] FUSIONS Reducing food waste through social innovation. "Estimates of European food waste levels" Stockholm 31 March 2016. ISBN 978-91-88319-01-2.

[3] A. Brizi and A. Biraglia, "Do I have enough food?How need for cognitive closure and gender impact stockpiling and food waste during the COVID-19 pandemic: A cross-national study in India and the United States of America" Pers. Individ. Differ., n. 168 (2021) 110396. https://doi.org/10.1016/j.paid.2020.110396

[4] V. Amicarelli and C. Bux, "Food waste in Italian households during the Covid-19 pandemic: a self-reporting approach" Food Sec., 6.11.2020. https://doi.org/10.1007/s12571-020-01121-z

[5] C. M. Galanakis, "The Food Systems in the Era of the Coronavirus (COVID-19) Pandemic Crisis", Foods, n. 9, p 523; doi:10.3390/foods9040523. 2020.

[6] R. Aldaco, D.Hoehna, J. Lasoa, M.Margalloa, J. Ruiz-Salmóna, J. Cristobal, R. Kahhat, P. Villanueva-Rey, A. Bala, L. Batlle-Bayer, P. Fullana-i-Palmer, A. Irabien, I. Vazquez-Rowe, "Food waste management during the COVID-19 outbreak: a holistic climate, economic and nutritional approach", Scie. Total Environ., 742.140524. https://doi.org/10.1016/j.scitotenv.2020.140524 0048-9697/2020.

[7] Communication From The Commission To The European Parliament, The European Council, The Council, The European Economic and Social Committee And The Committee Of The Regions. The European Green Deal. Brussels, 11.12.2019 COM (2019) 640 final

[8] Mitigating risks to food systems during COVID-19. Reducing food loss and waste. FAO 11 May 2020

[9] FAO. 2019. Food security and nutrition policy dialogues in Europe, the Caucasus and Central Asia 2016-2019 - a retrospective. Rome. ISBN 978-92-5-131989-5

[10] Van der Heijden and M. Kosters, "From mechanism to virtue: evaluating Nudge-theory", Reg. Net Working Paper, no. 80, Regulatory Institutions Network. 2015.

[11] R. Thaler and C. Sunstein, Nudge (revised edition). London: Penguin Reiss, R., and Thomas, M., eds. 2001. 2009.

[12] A. Arno and S. Thomas, "The efficacy of nudge theory strategies in influencing adult dietary behaviour: a systematic review and meta-analysis", BMC Public Health, n. 16, pp 676. 2016.

[13] S.Vallgarda, "A new and better way to improve health?", Health policy, n 104, pp 200-203. 2012.

[14] A. Segrè and S. Gaiani. "Lo spreco alimentare domestico in Italia: stime, cause ed impatti", Ph.D. dissertation, Economia e politica agraria ed alimentare $(24$ Ciclo $)$, Alma Mater Studiorum, Università di Bologna. DOI 10.6092/unibo/amsdottorato/5916. 2013.

[15] http://www.sprecozero.it/waste-watcher

[16] Technical Platform on the Measurement and Reduction of Food Loss and Waste (TPFLW): http://www.fao.org/platform-food-loss-waste/en/

[17] E. Sturchio, M. Zanellato, P. Boccia, C. Meconi, L. Cellai, V. Macino, U. Mazzanti, "A project exploring the reasons linked to consumer-related food waste, involving three Italian schools" in Proceedings of the Sixth International Conference on Environmental Management, Engineering, Planning \& Economics, Thessaloniki, Greece, June 25-30, 2017 ISBN: 978-618-5271-15-2. 2017 